\title{
Remote sensing of environmental change over China: A review
}

\author{
GONG Peng ${ }^{1,2}$ \\ ${ }^{1}$ Ministry of Education Key Laboratory for Earth System Modeling, Center for Earth System Science, Tsinghua University, Beijing 100084, China; \\ ${ }^{2}$ Division of Ecosystem Science, University of California, Berkeley, CA 94720-3114, USA
}

Received February 9, 2012; accepted March 30, 2012

\begin{abstract}
China is a large country by area. In situ monitoring of the environment cannot meet the demand of the society. For large areas, remote sensing is the only viable technology for environmental monitoring of the entire area. Although satellite observation capabilities as well as remotely sensed data acquired on board of satellites from both within and outside China are widely available, research is rare that targets the entire territory of China for environmental monitoring. In this paper, the process of environmental change has been categorized into changes in driving forces, environmental change, materials transport and transformation, concentration and abundance change, exposure and infection change of human and ecosystems, and impacts. The potential in monitoring changes in these various aspects is assessed. The progress of environmental change monitoring over the entire territory of China is reviewed. It is suggested that at the methodological level, remote sensing should not only be applied to observation and experiments as well as understanding the change mechanism, but also be coupled with environmental simulation and forecasting so as to support environmental policy making. At the application level, remote sensing should be used beyond its traditional application fields to include species diversity, biological invasion, public health, air and water quality monitoring. Finally, at the technical level, systematic research should be devoted to the improvement of operational and automatic use of remotely sensed data.
\end{abstract}

environmental change, remote sensing, China, simulation and prediction, environmental policy

Citation: Gong P. Remote sensing of environmental change over China: A review. Chin Sci Bull, 2012, 57: 2793-2801, doi: 10.1007/s11434-012-5268-y

Global environmental change is defined in the Earth System Science Partnership program by changes in the physical and biogeochemical changes especially caused by human activities [1]. For example, climate change and desertification in the arid and semi arid areas are examples of the physical system change [2-4]. Pollutions of the atmosphere, soil and water bodies are biogeochemical changes. Human drivers include deforestation, fossil fuel burning, urbanization, land reclamation, fertilization and pesticide use, fresh water extraction, over grazing and over harvesting of fishery in ocean and lakes, and waste production. Only when these changes accurately detected and identified, and their intensity and duration measured, can we better understand the underlying processes, simulate the past and forecast the future of these changes, and develop adequate policies for environmental management, restoration and adaptation, and

*email: penggong@tsinghua.edu.cn eventually reduce the negative impacts of these changes.

Conventional observation on environmental changes is limited to local areas or specific locations at certain limited times. For example, environmental observation data collected by the Ministry of Environment of China are only restricted to approximately 100 prefecture level cities. Weather data collected by the State Weather Administration are from approximately 2000 stations that are dozens to hundreds of km away. Measurements from different countries may suffer from different standards, use of different instruments and discrepancy in measurement density. Therefore, over large spatial areas, it is difficult to collect data that are consistent in accuracy and even in coverage. It is expensive to establish a comprehensive and systematic network of on-site observations over a large country like China. How to obtain accurate environmental change information over China is a challenge both China and the international society are facing. Although China's input in 
environmental monitoring had been increasing rapidly in the past 30 years, it is still lagging far behind the rate of economic development and the demand of general public. For example, before 2011, China does not monitor $\mathrm{PM}_{2.5}$ (particulate matter whose diameter is less than $2.5 \mu \mathrm{m}$ ).

Although the international society is aware of the shortcomings and uncertainties in data reported from aggregation of lower level administrative units, little can be done to change this because capitals and technology could both cause inconsistency in the items to be measured and the measurement accuracy. For example, the Food and Agriculture Organization of the United Nation (FAO) relied on the aggregating the reported forest cover numbers from individual countries for many years. Until 2011, it adopted a methodology to conduct forest change survey using the free of charge Landsat data made available by the United States. Based on a $1 \%$ sampling of all over the world, FAO obtained forest cover data for 1990, 2000, and 2005. When compared with the reported data by individual countries of the same year, it can be seen the totals differ by approximately $10 \%[5,6]$. It is easy to imagine that given the fact that the percentage difference is so large at the global scale the percent differences at local scale would usually be much greater.

For environmental change monitoring at large spatial scale, remote sensing is the only viable means. However, at the global scale, this technology only led to the production of a limited number of global data products from weather satellite data with a spatial resolution at the $\mathrm{km}$ scale $[7,8]$. Since the 21st century, China launched a number of advanced satellites including the China-Brazil Resource Satellite-2, Fengyun series of weather satellites, Haiyang series of ocean observation satellites, Huanjing environment and disaster monitoring satellite, and the satellite for surveying and mapping. However, technologies for data receiving and storage are somewhat backward with these Chinese satellites due to the lack of multiple ground receiving stations evenly distributed in different part of the world and the limited on-orbit data storing capacity. Nonetheless, as an important application field, remote sensing of environmental change over the entire territory of China, it faces considerably significant difficulties in transforming satellite data into meaningful information. To overcome these difficulties, an essential question that must be addressed is what types of environmental changes can be effectively monitored with satellite remote sensing. However, this requires comprehensive experiment and assessment of all possibilities before the question can be fully answered.

\section{Contents and methods in remote sensing of environmental changes}

The spatial scale for environmental change can be as small as a water pond, a crop field, a community or a small watershed, and can be as large as a continent, the entire earth or the universe. The temporal scale can be as short as subseconds as during an earthquake or lightening, minutes and hours during flooding and hurricane passing, or seasonal to interannual in vegetation growth, and can be as long as hundreds of years during ecosystem succession, millions of years of continental shift and up and downs of species evolution. The evolution cycle of human and ecosystems driven by environmental change and the interactions between environment and the human and ecosystem are summarized in Figure 1. It is possible to use remote sensing in many of the spatial-temporal processes in understanding these complex processes.

Environmental changes that might be detected with remote sensing are grouped into 6 categories (Table 1). This

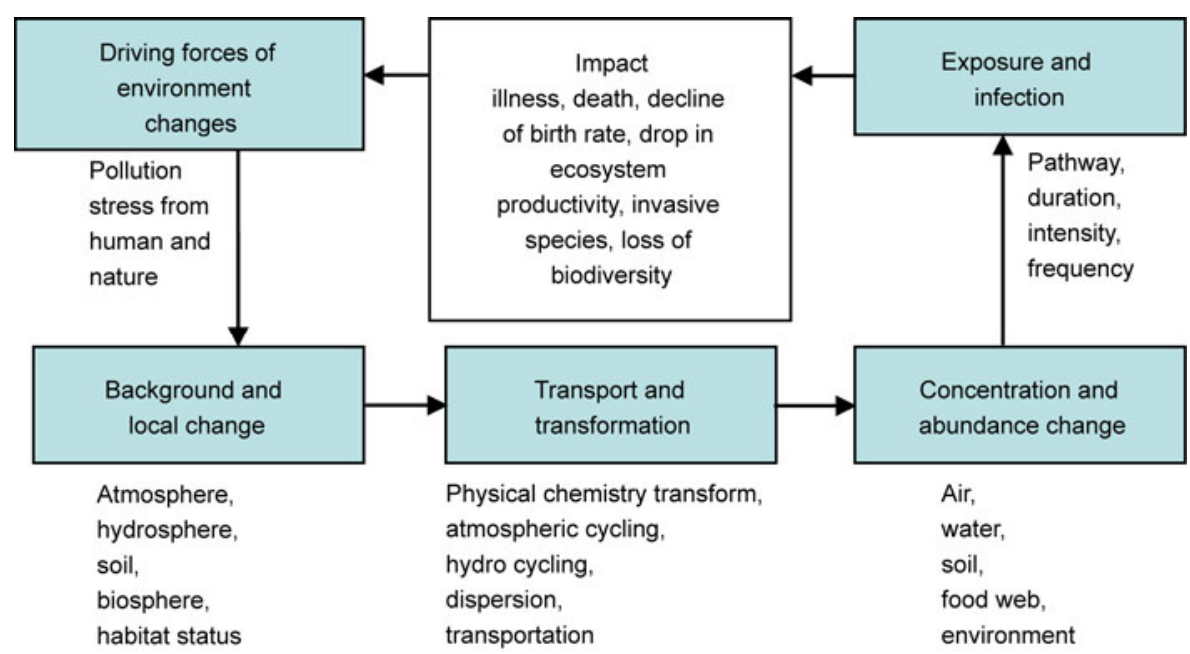

Figure 1 A simple sketch of the cycle environmental changes and their impacts on human and ecosystems. The actual process contains many multi-directional complex processes that are not plotted here. 
Table 1 Environmental change variables that are potentially detectable with remote sensing

\begin{tabular}{|c|c|}
\hline Broad categories & Types of environmental change \\
\hline Forest dominated environment & $\begin{array}{l}\text { Species, phenology, height and closure, species abundance, age, succession, climate adaption, meteorological hazards, fire, } \\
\text { disease, pollution, alien species invasion, pruning, selective logging, plantation, biomass, leaf area index, chlorophyll con- } \\
\text { tent/nitrogen content and other biogeochemical variables, forested wetland area, etc. }\end{array}$ \\
\hline $\begin{array}{l}\text { Shrubs and grassland domi- } \\
\text { nated environment }\end{array}$ & $\begin{array}{l}\text { Species, phenology, closure and height, species abundance, succession, adaptation to climate change, meteorological haz- } \\
\text { ards, fire, disease and insect attack, pollution, grazing, alien species invasion, leaf area index, plantation, productivity, etc. }\end{array}$ \\
\hline Agricultural environment & $\begin{array}{l}\text { Soil physical and chemical properties (type, temperature, moisture, organic matter, heavy metal concentration etc.), crop } \\
\text { type, plantation acreage, leaf area index, phenology, flooding and drought, disease and insect attack, pollution, fire, } \\
\text { productivity, etc. }\end{array}$ \\
\hline $\begin{array}{l}\text { Non-photosynthetically active } \\
\text { surfaces }\end{array}$ & Impervious surface, building density and height, roof material, type of road pavement, bare soil surface, etc. \\
\hline Water environment & $\begin{array}{l}\text { Water level height, inundation extent, underwater topography, temperature, waves, speed of current, suspended sediment, } \\
\text { salinity, turbidity, acidity, dissolved organic matter concentration, algae concentration, pollutant, alien species invasion, } \\
\text { species abundance, productivity, freezing and melting, length of freezing period, ice and snow cover types, thickness ex- } \\
\text { tent, etc. }\end{array}$ \\
\hline Atmospheric environment & $\begin{array}{l}\text { Temperature, humidity, pressure, wind speed and direction, atmospheric chemical constituents, concentration and vertical } \\
\text { distribution, aerosol optical depth, size and shape of particulate matter, the height, coverage, thickness and water vapor } \\
\text { content in clouds, lightening location and frequency, etc. }\end{array}$ \\
\hline
\end{tabular}

is a wish list that can be further deliberated by the science community. A lot of research and development is needed to reach the goal of effective monitoring of any single item. Underground variables are not considered here as they are much difficult to monitor with remote sensing from above. This could change as technology develops. For example, the water table depth and abundance of water may be inferred from vegetation growth and gravity changes, respectively through indirect estimation $[9,10]$.

In the type of environmental changes, qualitative changes in species, fire burnt area, water bodies, impervious surface, snow and ice cover are related to Land-Use and Land-Cover Change (LUCC). Some even suggest the land change science as a distinct field of science [11]. LUCC, links with the driver of human activities by the manifestation of land use on the earth surface, and with the natural environmental system by land cover (Figure 2). The directional pointing in Figure 2 is primarily reflecting the simplified cause and effect relationship. In reality, they are multi-directional. The content in Figure 2 is simplified not exhaustive. The detection of LUCC though remote sensing plays an important role in understanding and simulating the interaction between human activities and the natural processes.

The application of remote sensing to the monitoring and mapping of LUCC has been widely studied. The detection and identification of LUCC are usually obtained through thresholding multitemporal differences of remotely sensed data or post classification comparison [12-16]. Most other types of changes can be quantitatively characterized. Such changes can be directly obtained by comparing measurements taken at different times [17-19]. Comparison methods include statistical regression models [20-23], inversion of physical models [24-26], or data assimilation [27,28]. Changes through time can be obtained through differencing, ratioing, trend analysis and direct change identification [29,30].

\section{Progress in remote sensing of environmental change over China}

Similar to other countries in the world, China also relies on the bottom-up report system to collect environmental information. After 30 years of economic growth, China experienced significantly large environmental changes. The urbanization rate, carbon emission, fertilizer and pesticide use have all topped the world during this period. However, the capability in monitoring these environmental changes falls behind the speed of environmental changes itself. Therefore, it is highly desirable to develop advanced capabilities in environmental change monitoring over the entire territory of

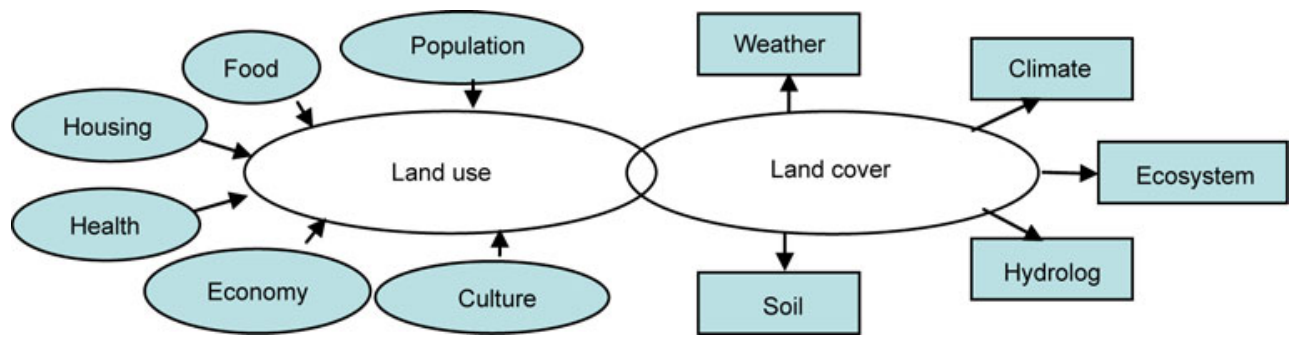

Figure 2 Land cover and land use change in relation to the human activity drivers and the natural system. 
China. It is reasonable to expect that satellite remote sensing should play an important role in environmental change monitoring over China.

However, a search of ISI Web of Knowledge using "environmental change and China and remote sensing" as the entry only resulted in 154 articles (February 4, 2012). When setting aside those focusing on local and individual cities, only about a dozen papers about the entire territory of China are left. Through manual interpretation of satellite images, China has already developed land cover and land use maps in the 1980s, 1990, 1995, 2000, and 2005. The 2010 land cover and land use map interpreted from satellite data is also underway. With these data, research has been done to study the changes of land use and their multiple impacts on the environment [31,32]. Methods have been developed to extract urban expansions from those interpreted land cover and land use maps in the 1990s, to understand the urban land use change processes, to summarize typical spatialtemporal urbanization patterns and to derive the differences in driving mechanisms of urban expansion [33]. Greenness indices derived from remotely sensed data were used in combination with ecosystem modeling and atmospheric inversion to derive the net primary productivity and carbon balance for China in 1980-1990s [34,35]. Regions of land degradation and improvement in 1981-2003 were identified through an analysis of greenness and NPP [36]. Using wetland maps derived from satellite image interpretation in circa 1990 and 2000, types of wetland changes in China were detected with area of wetland loss measured [37]. Although researchers have done a large amount of work in grain yield estimation using remotely sensed data in China, there are few relevant publications $[38,39]$. The spatial decomposition/interpolation has been done by converting county level population data to grids of $1 \mathrm{~km}^{2}$ based on those land use maps derived from remotely sensed data [40]. A combination of photo interpretation of lake water bodies with those digitized from historical topographic maps resulted in a database on lake body changes over a 50 year period for all lakes whose area exceeds $1 \mathrm{~km}^{2}$ in China [41]. Optical penetration depth over the continental shelf of the China sea has been measured with remote sensing and validated by on-site measurements for accuracy assessment [42].

In this special collection, a total of 7 papers on different aspects of environmental changes of China were included. They cover changes in time of China's urbanization, wetland, soil moisture, forest leaf area index, vegetation greenness, nitrate oxide and ozone. Their content and significance are briefly introduced below.

Construction material consumption exceeds half of the world production in the 21 st century and this trend is likely to continue until 2030 [43]. A significant portion of the construction materials has been used in urban development and transportation. China's urbanization improved citizen's life but at the same time caused congestion and increased effect of urban heat island [44], increased air pollution that threatens citizen's health $[45,46]$, increased heavy metal concentration in soils and degraded soil quality [47]. Therefore, how to urbanize in China has become the focus of the society [48]. However, what is the rate and spatial distribution of China's urbanization during the past 2 decades, particularly the first 10 years of the 21 st century remains to be answered. Wang et al. [49] interpreted urban areas using satellite data in circa 1990, 2000, and 2010 for all 663 cities in China including Hong Kong, Marco and those in Taiwan. This reveals the speed of urbanization, loss of agricultural lands, land use efficiency per unit gross domestic production, and population density of unit urbanized area during the past 2 decades over the entire China. This data set provides unique information on China's urban expansion. For urban planners and administrators, this new data set, independent of reported data through a bottom-up statistics, can provide relatively objective new evidence on China's urban development.

Along the line of wetland mapping, Niu et al. [50] not only extended the manual interpretation of wetland from satellite images to circa 1978 and 2008 based on earlier mapping of 1990 and 2000, but also did field visits over 10 areas of China in 2008 and 2009 to increase field data in support of the manual interpretation of satellite images. Additionally, a large amount of consistency checking has been done by overlaying all 4-time wetland maps to reduce uncertainties. As a result, a wetland dataset spanning over 1978-2008 in circa 1978, 1990, 2000, and 2008 was completed with consistent quality control. Wetland changes in this period have been obtained by comparing the wetland maps from consecutive times. In 1992, China joined the Ramsar international convention on wetland protection. Soon a large number of wetland protection areas have been established. The wetland change data set enabled the assessment of protection efficacy of 91 national wetland reserves [51].

The per capita fresh water resource in China is far below the world average. Although there is severe lack of freshwater in Northern China, the center of agricultural production has been migrating northward in the past 20 years [52]. The frequent draughts in recent years in China constitute severe threats to the food security, ecological security and even national security of China. Although China has installed a large number of water gauge stations and soil moisture stations, it is not possible to reflect the spatialtemporal variation of soil moisture over China. Lu and Shi [53] compared three sets of monthly average soil moisture data from 2003 to 2010 over entire China derived from the same set of microwave radiometry data with three different algorithms. The spatial resolution is $25 \mathrm{~km}$. By normalizing the three sets of data and ensemble analysis, they developed an integrated set of soil moisture data. Compared with precipitation data, soil moisture data reflects the actual soil water availability over the top layer of the soil and it is the result of water redistribution following hydrological cycling 
and modification by terrain and surface vegetation. It is more closely related to vegetation growth. A linear fit to the temporal profile of the soil moisture data indicate the trend of surface water towards dry (decrease) or humid (increase). This trend overlaid with surface temperature trend allows the determination of water and energy trend of an area. An area becoming wetter and warmer would definitely increase the land productivity. In arid regions where water is the determining factor of plant growth, a wetter trend combined with gentle decline of temperature would also increase land productivity. A drier soil is generally unfavorable to land productivity. Their results indicate that in the eastern region dominated by grain production, southern China is experiencing a drying and warming trend over the 2003-2010 period, while northern China is experiencing a drying and cooling trend, neither is favorable to agricultural productivity.

There exists a positive correlation between vegetation growth and vegetation indices derived from satellite data. Vegetation indices are often used to derive leaf area index, as well as NPP. In relatively dry area, the crop closure is highly correlated to vegetation indices, and thus is related to the greenness of such a region. Therefore, sometimes, vegetation index is considered as a proxy to greenness. Many studies used vegetation index to analyze vegetation growth in various regions of China, but those mostly used data before 2003. Liu and Gong [54] used $500 \mathrm{~m}$ resolution vegetation index data derived from Moderate Resolution Imaging Spectrometer (MODIS) data for the growing season of 2000 and 2010. An 11 year trend analysis indicates overall China is greener during this period. Desert areas have a shrinking trend. However, greenness over some agricultural areas in eastern China is experiencing a decline possibly due to urban expansion [49].

Leaf area index (LAI) is an important indicator of ecosystem status and ecosystem productivity. It is also the basis for NPP estimation and carbon balance studies. Methods for estimating LAI from remotely sensed data evolved from establishing empirical statistical relations with LAI [55] to inversion of radiative transfer models. By inverting a specific radiative transfer model - 4-scale geometric optical model [56] and inverting leaf clumping from remotely sensed data [57], Liu et al. [58] derived forest LAI for the entire China based on $500 \mathrm{~m}$ resolution MODIS data during 2000-2010. Based on validation over 6 typical forest ecosystems in China, their resultant $R^{2}$ ranges from 0.69 and 0.80 . This is the highest resolution, most reliable long term forest LAI data product for entire China. Trend analysis 2000-2010 indicates that except western China, part of Zhejiang, Fujian and Guangdong provinces, forest LAI over the majority of China is increasing. Low temperature, high cloudiness, high temperature and drought are the primary reasons for the relatively low annual average forest LAI in 2001 and 2009.

The atmospheric condition in China is deteriorating as the economic growth. Recently, more attention has been paid to remote sensing observation of atmospheric conditions as a new type of technology [59-64]. Zhang et al. [65] collected nitrate oxide concentration data product calculated from satellite remote sensing for the atmospheric columns over China for 1996-2010. Change analysis indicates that an increasing trend of nitrate oxide concentration is observed not only over large municipalities but also over medium sized cities. The high concentration regions tend to merge with time going forward to form bigger and bigger regions. Newly emerged high concentration areas exceed far beyond the state planned key pollution control areas. This new discovery provides important new information for the Ministry of Environment in their atmospheric pollution control policy development. Nitrate oxide is the precursor of surface air pollutant ozone. Shen and Wang [66] collected monthly average ozone concentration data product derived from the Tropospheric Emission Spectrometer data on board of Aura satellite from 2005 to 2010. They investigated changes in ozone concentration at three different heights in the troposphere over Northern and Southern China and two heights over western China. They found seasonal differences in ozone concentration trends. Ozone concentration is increasing in western China and particularly Northern China. The change in southern China is slow and near surface ozone concentration is even decreasing. These differences derived from satellite remote sensing have important implication in better understanding of the spatial temporal distribution of ozone in the troposphere and the causes of ozone formation.

Although the data used and the application purpose may be different, data and results among several papers in this special collection can be used for comparison and validation purposes. An analysis of weather stations over China indicate that during 2000 and 2010, most stations record an warming trend while precipitation among half of the stations has a drying trends and half does not. From Figure 6 in Liu and Gong [54] it can be seen that most weather stations in Northern China have an increase trend in precipitation while in most of Xinjiang, southeast of Tibet, Yunnan, hilly regions of Southern China, Ningxia, Henan and southeast of Inner Mongolia become drier. Although precipitation is redistributed following gravity and thus their spatial distribution cannot fully represent the actual water balance and thus will not fully explain the growing condition of vegetation, the Figure 4 in Liu et al. [58] indicates most of the wetter areas estimated an increase trend in forest LAI. The increase in forest LAI is obvious in Heilongjiang, Northern Hebei, Shaanxi, Shanxi, Hubei, Chongqing, Guizhou, Guangxi, Hainan and Taiwan. This is also consistent with Figure 2 in [54]. Because satellite data used in these two studies are the same, it is understandable to reach these agreements. Recent research report that the forest plantation has largely increased in Jiangsu [67], but this cannot be detected from either studies $[54,58]$. Because the resolution used in these two studies [54,58] are $500 \mathrm{~m}$, and the forest distribution data used in [58] are based on global land cover mapping in 
2000 using satellite data at $1 \mathrm{~km}$ resolution, it is reasonable that the relatively smaller land parcel and young plantation in Jiangsu may not be detectable. The large scale aforestation in China is often reported in recent years but no spatial distribution map is released from governmental sources. Since the forest map produced from international sources contain a large amount of uncertainty, China must have more detailed forest map for research and policy making purposes. Changes in the annual soil moisture distribution trend in [53] based on microwave radiometer data obtained in the period of 2003-2010 agree well with Figure 6 in [54]. However, the drier area is greater including the middle and lower ranches of Yangtze River basin, eastern and northern China. This covers the primary agricultural land in China. The governmental report gives a continuing increase in grain production between 2004 and 2011. In Figure 2 of [54] the greening trend of the primary agricultural area can be observed. Agricultural production in Northern China is primarily relying on ground water. Since the between 2000 and 2010 , the primary grain production area is becoming wetter according to precipitation except Henan Province. Why this is not identifiable from the microwave data [53]? If the forest LAI study [58] can be expanded into the agricultural area, we would have another piece of information to investigate the agricultural productivity with remote sensing in China. This question centering around whether the grain production report from the government is trustable or not is worth further studies. Only if we can further improve the inversion accuracy of environmental variables, better understand the climate, hydrological cycle and soil moisture distribution in China, can we better understand the driving mechanism of the greenness trend in China. It is worth noting that due to the relatively coarse spatial resolution in remotely sensed data used for large area mapping, validation of inversion results is extremely difficult. Except validation data from 6 study sites were used to validate forest LAI in Liu et al. [58] no validation were undertaken in the remaining studies in this special collection. This is a major shortcoming of these papers. Because the source data were obtained from abroad, although the algorithms may be validated in other countries, the validity of these data needs to be further investigated.

\section{Perspectives}

Based on the current status of global change in China, Xu et al. [68] proposed a prioritized list of issues to be addressed in future studies. These include the interaction of global change and human activities, earth system models, earth observation and economics issues of global change. A year later, $\mathrm{Xu}$ et al. [69] call for the Chinese earth scientists to use improved understanding of China to study the scientific issues of the entire globe. They pointed out that Chinese scientists should have a global vision, interdisciplinary and quantitative skills and open to data sharing. All these are relevant to the study of remote sensing of environmental changes over China.

First, a research framework needs to be established to deepen the development of methodology in environmental change remote sensing. As in Figure 3, the purpose of experimental observation is to improve scientific understanding of the phenomena under study. This is a frequently used method in environmental change remote sensing. It is desirable to form new theories from observation [70-72], or through what we learnt from observational data to improve technology [73]. However, in studies on environmental change remote sensing, use of simulation and modeling techniques is insufficient. Admittedly, errors could occur in both observation [53,74-76] and modeling [77] but the combination of observation and modeling results may often lead to new understandings [78,79]. In addition, research concerning the connection between results from environmental change remote sensing and environmental policy is rare. This needs to be strengthened. Papers in this special collection have strong implication with environmental policy making and terrestrial planning $[49,50,53,54,65]$.

Second, the application fields of environmental change remote sensing should be further expanded. When Figure 1 and Table 1 are compared, we can find that many variables

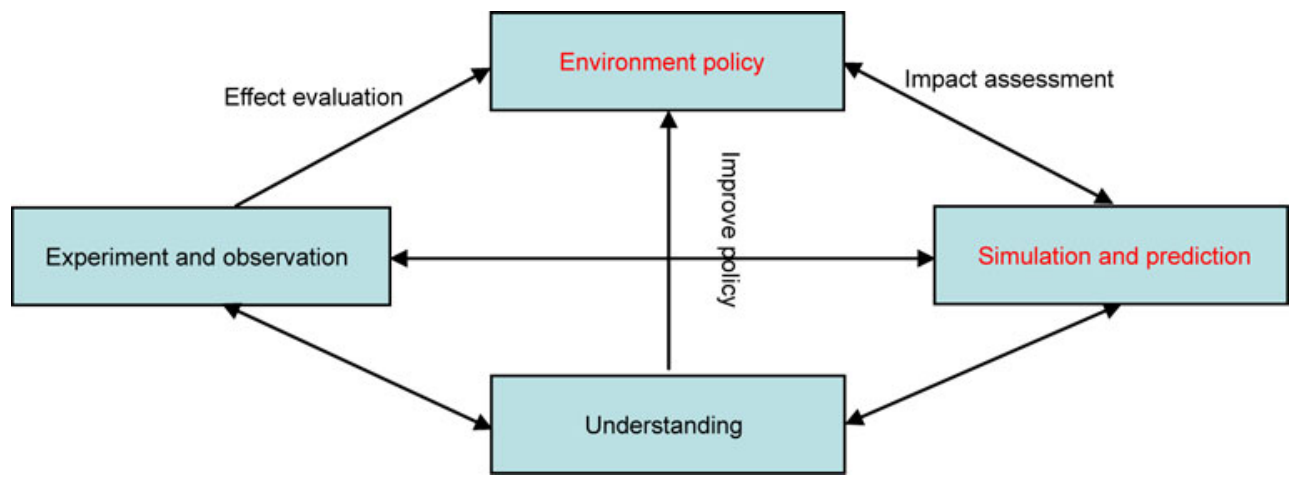

Figure 3 The methodology framework for environmental change remote sensing. 
are not studied over the entire Chinese territory. Using the forest dominated environment as an example, species abundance, forest age, alien species invasion, forested wetland, and climate adaption are hardly studied in China. Water pollution over China is another gap for remote sensing studies. The most significant impact of environmental change is public health. However, except for avian influenza, schistosomiasis and malaria [80-83] there are few studies involving remote sensing over China [84,85]. Atmospheric pollution cause health damages not only to urban residents but also to rural citizens [86]. However, huge gaps exist over rural areas in environmental monitoring. Remote sensing could play an indispensible role in atmospheric pollution monitoring in rural China. Among the many indicators affecting food security in China, there is even not a total cropland area statistics based on remote sensing. Many studies must use the highly debatable figure of crop land area provided in the governmental report [87].

Third, new information extraction algorithms need to be developed for new applications. There is still room to further improve algorithms for information extraction from remotely sensed data, particularly over large areas. Remote sensing data used for monitoring environmental changes heavily rely on sources from polar orbit satellites. A single path of polar orbit satellites can acquire a swath of 10 to $2400 \mathrm{~km}$. Due to cloud cover and other atmospheric interference, it usually takes a long time to have a complete coverage of useable data. The inconsistency in data acquisition time, terrain effects and solar angles adds a considerable amount of radiometric variation to certain targets of interest. A large amount of radiometric calibration and geometric correction needs to be done. Particularly for the new satellites launched by China, new algorithms for radiometric and geometric processing need to be developed and evaluated. In addition, as different types of remotely sensed data are becoming increasingly available, more research is need to integrate, fuse and apply data from multiple sources so as to reduce the uncertainty in extracted information [88]. Lastly, algorithm development benefits from interdisciplinary research. For example, as the data volume is becoming increasingly large, new ways of efficient data processing may be needed from the use of high performance computing. This would clearly benefit from collaborating with high performance computing specialists traditionally in the computer science discipline.

Finally, a further step must be taken from emphasizing on experimental test and technology development to striving for practical use of various remote sensing technologies. Operational use by end-users in the science community, industries and governmental agencies should the ultimate goal of environmental change remote sensing. We must be able to provide scientific evidence when needed as exemplified in [89] in solving a scientific dispute on the glacier retreat and advance in the Himalayas. There are a lot to do in the field of remote sensing of China's environmental changes.
Weimin Ju, Yuxuan Wang, Qiang Zhang, and Zhenguo Niu provided comments on an earlier draft of this manuscript. Two anonymous reviewers provided constructive suggestions. This work was supported by the National High Technology R\&D Program of China (2009AA12200101).

1 Leemans R, Asrar G, Busalacchi A, et al. Developing a common strategy for integrative global environmental change research and outreach: The Earth System Science Partnership (ESSP) Strategy Paper. Curr Opin Env Sust, 2009, 1: 4-13

2 Ci L J. Desertification of extra-arid desert (in Chinese). Chin Sci Bull (Chin Ver), 2011, 56: 2616-2626

3 Cracknell A P, Varotsos C A. New aspects of global climate- dynamics research and remote sensing. Int J Remote Sens, 2011, 32: 579-600

4 Li J F, Wang M H, Ho Y S. Trends in research on global climate change: A science citation index expanded-based analysis. Glob Planet Change, 2011, 77: 13-20

5 FAO. Global Forest Land-Use Change from 1990 to 2005. 2011

6 FAO. State of the World's Forests, Rome, Italy, 2011. 179

7 Nemani R R, Keeling C D, Hashimoto H, et al. Climate-driven increases in global terrestrial net primary production from 1982 to 1999 Science, 2003, 300: 1560-1563

8 Behrenfeld M J, O'Malley R T, Siegel D A, et al. Climate-driven trends in contemporary ocean productivity. Nature, 2006, 444: 752755

9 Rodell M, Velicogna I, Famiglietti J S. Satellite-based estimates of groundwater depletion in India. Nature, 2009, 460: 999-U80

10 Gong P, Miao X, Ge S K, et al. Water table level in relation to EO-1 ALI and Landsat ETM+ data over a mountainous meadow in California. Can J Remote Sens, 2004, 32: 691-696

11 Turner B L, Lambin E F, Reenberg A. The emergence of land change science for global environmental change and sustainability. Proc Natl Acad Sci USA, 2007, 102: 20666-20671

12 Lu D, Weng Q. A survey of image classification methods and techniques for improving classification performance. Int J Remote Sens, 2007, 28: 823-870

13 Tucker C J, Townshend J R G, Goff T E. African land-cover classification using satellite data. Science, 1985, 227: 369-375

14 Pu R L, Li Z Q, Gong P, et al. Development and analysis of a 12-year daily $1-\mathrm{km}$ forest fire data across the North America from NOAA/ AVHRR data. Remote Sens Environ, 2007, 108: 198-208

15 Clinton N, Gong P, Jin Z Y, et al. Meta-prediction of Bromus tectorum invasion in Central Utah, U.S.A. Photogramm Eng Remote Sens, 2009, 75: 689-701

16 Herold M, Mayaux P, Woodcock C E, et al. Some challenges in global land cover mapping: An assessment of agreement and accuracy in existing $1 \mathrm{~km}$ datasets. Remote Sens Environ, 2008, 112: 2538-2556

17 Gong P, Sheng Y W, Biging G S. 3D model-based tree measurement from high resolution aerial imagery. Photogramm Eng Remote Sens, 2002, 68: 1203-1212

18 Chen Q, Gong P, Baldocchi D, et al. Filtering airborne laser scanning data with morphological methods. Photogr Eng Remote Sens, 2007, 73: $175-185$

19 Sun G Q, Ranson K J, Guo Z, et al. Forest biomass mapping from lidar and radar synergies. Remote Sens Environ, 2011, 115: 29062916

20 Lo C P, Welch R. Chinese urban-population estimates. Ann Assoc A, 1977, 67: 246-253

21 Hansen M C, DeFries R, Townshend J. Towards an operational MODIS continuous field of percent tree cover algorithm: Examples using AVHRR and MODIS data. Remote Sens Environ, 2002, 83: 303-319

22 Gong P, Pu R L, Miller J R. Coniferous forest leaf area index estimation along a transect in Oregon using Compact Airborne Spectrographic Imager data. Photogr Eng Rem S, 1995, 61: 1107-1117

23 Michishita R, Gong P, Xu B. Spectral mixture analysis for bi-sensor wetland mapping using Landsat TM and Terra MODIS data. Int J Remote Sens, 2012, 33: 3373-3401 
24 Li X W, Gao F, Wang J D. A priori knowledge accumulation and its application to linear BRDF model inversion. J Geophys Res, 2001, 106: 11925-11935

25 Liang S L, Strahler A H. An analytic brdf model of canopy radiativetransfer and its inversion. IEEE T Geosci Remote, 1993, 31: 10811092

26 Shi J C, Jackson T, Tao J, et al. Microwave vegetation indices for short vegetation covers from satellite passive microwave sensor AMSR-E. Remote Sens Environ, 2008, 112: 4285-4300

27 Liang S L. Quantitative Remote Sensing of Land Surfaces. New York: John Wiley and Sons, Inc, 2004. 534

28 Qin J, Liang S L, Liu R G, et al. A weak constraint based data assimilation for estimating surface turbulent fluxes. IEEE Geosci Remote Sens, 2007, 4: 649-653

29 Lu D S, Mausel P, Brondizio E, et al. Change detection techniques. Int J Remote Sens, 2004, 25: 2365-2407

30 Liu D S, Cai S S. A spatial-temporal modeling approach to reconstructing land-cover change trajectories from multi-temporal satellite imagery. Ann Assoc A, 2011, doi: 10.1080/00045608.2011.596357

31 Liu J Y, Liu M L, Tian H Q, et al. Spatial and temporal patterns of China's cropland during 1990-2000: An analysis based on Landsat TM data. Remote Sens Environ, 2005, 98: 442-456

32 Liu J Y, Deng X Z. Progress of the research methodologies on the temporal and spatial process of LUCC. Chin Sci Bull, 2010, 55: 1354-1362

33 Liu J Y, Zhan J Y, Deng X Z. The Spatio-temporal patterns and driving forces of urban land expansion in China during the economic reform era. AMBIO, 2005, 34: 450-455

34 Piao S L, Fang J Y, Ciais P. The carbon balance of terrestrial ecosystems in China. Nature, 2009, 458: 1009-u82

35 Feng X, Liu G, Chen J M, et al. Net primary productivity of China's terrestrial ecosystems from a process model driven by remote sensing. J Environ Manage, 2007, 85: 563-573

36 Bai Z G, Dent D. Recent land degradation and improvement in China. AMBIO, 2009, 38: 150-156

37 Gong P, Niu Z G, Cheng X, et al. China's wetland change (19902000) determined by remote sensing. Sci China Earth Sci, 2010, 53: 1036-1042

38 Sun J L. Dynamic monitoring and yield estimation of crops by mainly using the remote sensing technique in China. Photogramm Eng Remote Sens, 2010, 66: 645-650

39 Xiao X M, Liu J Y, Zhuang D F, et al. Uncertainties in estimates of cropland area in China: A comparison between an AVHRR-derived dataset and a Landsat TM-derived dataset. Glob Planet Change, 2003, 37: 297-306

40 Zhuang D F, Liu M L, Deng X Z. Spatialization model of population based on dataset of land use and land cover change in China. Chin Geogr Sci, 2002, 12: 114-119

41 Ma R H, Duan H T, Hu C M, et al. A half-century of changes in China's lakes: Global warming or human influence? Geophys Res Lett, 2010, 37: L24106

42 Shang S L, Lee Z P, Wei G M. Characterization of MODIS-derived euphotic zone depth: Results for the China Sea. Remote Sens Environ, 2011, 115: 180-186

43 Fernandez J E. Resource consumption of new urban construction in China. J Ind Ecol, 2007, 11: 99-115

44 Yang X C, Hou Y L, Chen B D. Observed surface warming induced by urbanization in east China. J Geophys Res, 2011, 116: D14113

45 Zhao Y, McElroy M B, Xing J, et al. Multiple effects and uncertainties of emission control policies in China: Implications for public health, soil acidification, and global temperature. Sci Total Environ, 2011, 409: 5177-5187

46 Zhang F Y, Wang W Y, Lv J M. Time-series studies on air pollution and daily outpatient visits for allergic rhinitis in Beijing, China. Sci Total Environ, 2011, 409: 2486-2492

47 Zhang J, Pu L J, Peng B Z, et al. The impact of urban land expansion on soil quality in rapidly urbanizing regions in China: Kunshan as a case study. Environ Geochem Health, 2011, 33: 125-135

48 Siciliano G. Urbanization strategies, rural development and land use changes in China: A multiple-level integrated assessment. Land Use Policy, 2012, 29: 165-178

49 Wang L, Li C C, Ying Q, et al. China's urban expansion from 1990 to 2010 determined with satellite remote sensing. Chin Sci Bull, 2012, 57: 2802-2812

50 Niu Z G, Zhang H Y, Wang X W, et al. Mapping wetland changes in China between 1978 and 2008. Chin Sci Bull, 2012, 57: 2813-2823

51 Zheng Y M, Zhang H Y, Niu Z G, et al. Protection efficacy of national wetland reserves in China. Chin Sci Bull, 2012, 57: 207-230

52 Yu C Q, Gong P, Yin Y Y. China's water crisis needs more than words. Nature, 2011, 470: 307

$53 \mathrm{Lu} \mathrm{H}$, Shi J C. Reconstruction and analysis of temporal and spatial variations in surface soil moisture in China using remote sensing. Chin Sci Bull, 2012, 57: 2824-2834

54 Liu S, Gong P. Change of surface cover greenness in China between 2000 and 2010. Chin Sci Bull, 2012, 57: 2835-2845

55 Gong P, Pu R L, Biging G S, et al. Estimation of forest leaf area index using vegetation indices derived from Hyperion hyperspectral data. IEEE T Geosci Remote, 2003, 41: 1355-1362

56 Deng F, Chen J M, Plummer S, et al. Algorithm for global leaf area index retrieval using satellite imagery. IEEE T Geosci Remote, 2006, 44: 2219-2229

57 Zhu G L, Ju W M, Chen J M, et al. Foliage clumping index over China's landmass retrieved from the MODIS BRDF parameters product. IEEE T Geosci Remote, 2011, doi:10.11091TGRS.2011. 2172213

58 Liu Y B, Ju W M, Chen J M, et al. Spatial and temporal variations of forest LAI over China during 2010-2010. Chin Sci Bull, 2012, 57: 2846-2856

59 Wang Z F, Chen L F, Tao J H, et al. Satellite-based estimation of regional particulate matter (PM) in Beijing using vertical-and-RH correcting method. Remote Sens Environ, 2010, 114: 50-63

60 Cheng T H, Gu X F, Xie D H, et al. Simultaneous retrieval of aerosol optical properties over the Pearl River Delta, China using multi-angular, multi-spectral, and polarized measurements. Remote Sens Environ, 2011, 115: 1643-1652

61 Wang X L, Mannaerts C M, Yang S T, et al. Evaluation of soil nitrogen emissions from riparian zones coupling simple process-oriented models with remote sensing data. Sci Total Environ, 2010, 408: 3310-3318

62 Li Z Q, Chen H, Cribb M, et al. Preface to special section on east Asian studies of tropospheric aerosols: An international regional experiment (EAST-AIRE). J Geophys Res, 2007, 112: D22S00

63 Wang S W, Streets D G, Zhang Q, et al. Satellite detection and model verification of $\mathrm{NO}(\mathrm{x})$ emissions from power plants in Northern China. Environ Res Lett, 2010, 5: 044007

64 Wang Y, Zhang Y, Hao J, et al. Seasonal and spatial variability of surface ozone over China: Contributions from background and domestic pollution. Atmos Chem Phys, 2011, 11: 3511-3525

65 Zhang Q, He K B, Geng G N, et al. Satellite remote sensing of changes in $\mathrm{NO}_{x}$ emissions over China during 1996-2010. Chin Sci Bull, 2012, 57: 2857-2864

66 Shen L L, Wang Y X. Changes in tropospheric ozone levels over the Three Representative Regions of China observed from space by Tropospheric Emission Spectrometer (TES), 2005-2010. Chin Sci Bull, 2012, 57: 2865-2871

67 Shi L, Zhao S Q, Tang Z Y, et al. The changes in China's forests: An analysis using the forest identity. PLoS One, 2011, 6: e20778

$68 \mathrm{Xu} \mathrm{G} \mathrm{H,} \mathrm{GongP,} \mathrm{Shao} \mathrm{L} \mathrm{Q,} \mathrm{et} \mathrm{al,} \mathrm{Four} \mathrm{prioritized} \mathrm{research} \mathrm{area} \mathrm{of}$ global change research that need to be strengthened in China (in Chinese). Review of Global Change Research, First Vol, Beijing: Higher Education Press, 2010. 1-11

69 Xu G H, Ju H B, He B, et al. 21st century Chinese earth science development: based on China, towards the world (in Chinese). Sci Technol Daily, 2010-8-1

70 Behrenfeld M J. Abandoning Sverdrup's critical depth hypothesis on phytoplankton blooms. Ecology, 2010, 91: 977-989

71 Myneni R B, Keeling C D, Tucker C J, et al. Increased plant growth in the northern high latitudes from 1981 to 1991. Nature, 1997, 386: 
698-702

72 Samanta A, Costa M H, Nunes E L, et al. Comment on "droughtinduced reduction in global terrestrial net primary production from 2000 through 2009". Science, 2011, 333: 1093

73 Liang L, Xu B, Chen Y L, et al. Combining spatial-temporal and phylogenetic analysis approaches for improved understanding on global H5N1 transmission. PLoS One, 2010, 5: e13575

74 White M A, de Beurs K M, Didan K, et al. Intercomparison, interpretation, and assessment of spring phenology in North America estimated from remote sensing for 1982-2006. Glob Change Biol, 2009, 15: 2335-2359

75 Garrity S R, Bohrer G, Maurer K D, et al. A comparison of multiple phenology data sources for estimating seasonal transitions in deciduous forest carbon exchange. Agr Forest Meteorol, 2011, 151: 1741-1752

76 Jones M O, Jones L A, Kimball J S, et al. Satellite passive microwave remote sensing for monitoring global land surface phenology. Remote Sens Environ, 2011, 115: 1102-1114

77 Zhao M S, Running S W. Drought-induced reduction in global terrestrial net primary production from 2000 through 2009. Science, 2010, 329: 940-943

78 Sellers P J, Meeson B W, Hall F G, et al. Remote-sensing of the landsurface for studies of global change-models, algorithms, experiments. Remote Sens Environ, 1995, 51: 3-26

79 Piao S L, Ciais P, Friedlingstein P, et al. Net carbon dioxide losses of northern ecosystems in response to autumn warming. Nature, 2008, 451: 49-U3

80 Fang L Q, de Vlas S J, Liang S, et al. Environmental factors contributing to the spread of avian influenza in mainland China. PLoS One,
2008, 3: e2268

81 Spear R C, Seto E Y W, Carlton E J, et al. The challenge of effective surveillance in moving from low transmission to elimination of schistosomiasis in China. Int J Parasitol, 2011, 41: 1243-1247

82 Zhou X N, Yang G J, Yang K, et al. Potential impact of climate change on schistosomiasis transmission in China. Am J Trop Med Hyg, 2008, 78: 188-194

83 Yang G J, Gao Q, Zhou S S, et al. Mapping and predicting malaria transmission in the People's Republic of China, using integrated biologydriven and statistical models. Geospatial Health, 2010, 5: 11-22

84 Zhang J F, Mauzerall D L, Zhu T, et al. Environmental health in China: Progress towards clean air and safe water. Lancet, 2010, 375: 1110-1119

85 Gong P, Liang S L, Carlton E, et al. Urbanization and health in China. Lancet, 2012, 379: 843-852

86 Smith K R, McCracken J P, Weber M W, et al. Effect of reduction in household air pollution on childhood pneumonia in Guatemala (RESPIRE): A randomised controlled trial. Lancet, 2011, 378: 17171726

87 Fan M S, Shen J B, Yuan L X, et al. Improving crop productivity and resource use efficiency to ensure food security and environmental quality in China. J Environ Bot, 2012, 63: 13-24

88 Lv Y H, Fu B J, Wei W. Major ecosystems in China, dynamics and challenges for sustainable management. Environ Manage, 2011, 48: 13-27

89 Scherler D, Bookhagen B, Strecker M R. Spatially variable response of Himalayan glaciers to climate change affected by debris cover. Nat Geosci, 2011, 4: 156-159

Open Access This article is distributed under the terms of the Creative Commons Attribution License which permits any use, distribution, and reproduction in any medium, provided the original author(s) and source are credited. 